\title{
New guide helps doctors in radiation emergency
}

$\mathrm{T}$

he ripple effects of a nuclear accident in Japan that disabled three reactors and required the evacuation of about 300000 people have been felt in Canada. Four years after the Fukushima Daiichi meltdown, Health Canada has released its Canadian Guide on Medical Management of Radiation Emergencies to help physicians and other health professionals, as well as hospitals and emergency planners, better prepare for and manage the medical aspects of a radiation emergency.

"[We] recognized the need to better communicate and harmonize the practices used in the medical management of radiation emergencies across jurisdictions," says Health Canada spokesperson Sylwia Krzyszton.

The guide is a first in Canada. Although some hospital emergency departments have developed their own procedures for the management of radioactively contaminated casualties, the federal government, until now, had not offered up formal direction or assistance. "For guidance on the treatment of radiation injuries, there has been a reliance on US and European publications. These guidelines are not always applicable in Canada because of differences in the availability of specific resources or drugs," says Krzyszton.

The new publication, developed jointly by Health Canada and the Department of National Defence, provides a framework that hospitals, pub-

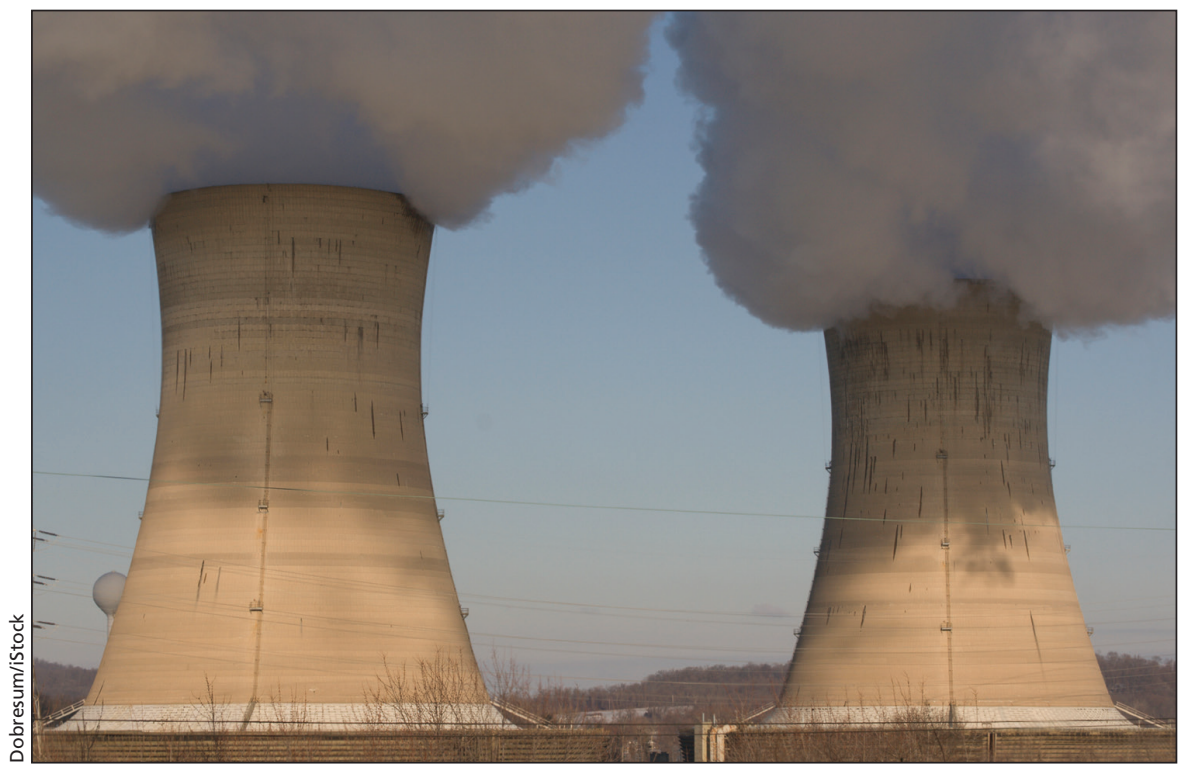

Health Canada's new guide will help health care providers manage the medical aspects of a radiation emergency.

lic health authorities and emergency organizations can base their response plans on. The full spectrum of medical management, from point-of-injury to long-term follow-up, is included in the guide, which Krzyszton calls "a valuable resource for physicians."

The main focus, however, is on the early medical management of radiation emergencies during the prehospital and emergency department responses. The former includes a public health approach for population screening and decontamination in community reception centres that was originally developed by the US Centers for Disease Control and Preven- tion. The latter provides information on preparation of the emergency departments, protection of hospital workers, triage of radiation casualties, patient decontamination and medical management of radiation casualties.

Technical information, such as procedures for contamination control and decontamination, emergency department set-up and casualty assessment, and forms for ordering specialized tests are also included in the guide, which is available in both English and French. — donalee Moulton, Halifax, NS

CMAJ 2015. DOI:10.1503/cmaj.109-5126 